\title{
Impact of long working hours on health based on observations in China
}

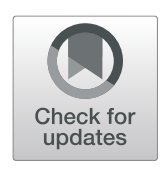

\author{
Liming Chu
}

\begin{abstract}
Background: Health should be a key focus in considerations of long working hours. Little is known about for which groups of people working longer hours is more harmful to their health. Additionally, the definition of long working hours varies slightly due to country differences in working hours systems. Therefore, this study aims to explore the association between long working hours and the self-rated health (SRH) level, taking into account gender and educational differences.

Method: Data were collected from two waves (2016 and 2018) of the China Family Panel Studies (CFPS). A total of 6972 workers were available for analysis. Descriptive statistical analysis, an ordered probit (oprobit) model and conditional mixed process (CMP) regression analyses were used to analyze the data. Furthermore, I conducted a stratified analysis by gender and education groups.

Result: This study observed a negative association between long working hours and SRH. Compared to other education groups, labor with long working hours had a more negative impact on the SRH of those with higher education. Long working hours had a more negative influence on the SRH of male workers. In contrast, no clear association was found among female workers.

Conclusion: This study estimates SRH of those with long working hours in China. Among workers, long working hours have a negative impact on the health of workers with college degrees or beyond. One possible explanation is that they do not exercise, their diet is unreasonable, and their working conditions involve chronic exposure to computer radiation. The negative health effects of long working hours on males are four times greater than those on females. This study provides valuable insights into the health of the workforce, working time regulations and overtime rules.
\end{abstract}

Keywords: Long working hours, Self-rated health, CMP, China

\section{Background}

In the era of fast economic development, the quality of the labor force has drawn widespread attention, and in this regard, health is an important factor. In recent years, excessive labor has slowly become common due to the continuously extended working hours of workers, which have a direct impact on their health level and harms economic development and social stability. A better

Correspondence: xiaoming@cueb.edu.cn

School of Labor Economics, Capital University of Economics and Business, Beijing 100070, China

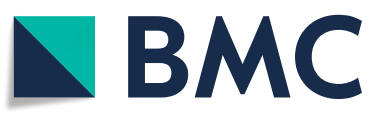

scholarly understanding of this topic appears to be urgently needed. China published the Health China 2030 plan, which aims to provide every citizen with health services by 2030. China's basic medical insurance system has reached the goal of covering both urban and rural residents, meeting their medical needs, and providing a strong guarantee for the improvement of workforce health. Understanding the impact of labor market performance on health holds great significance for exploring the influencing factors in the health level of the labor force.

(c) The Author(s). 2021 Open Access This article is licensed under a Creative Commons Attribution 4.0 International License, which permits use, sharing, adaptation, distribution and reproduction in any medium or format, as long as you give appropriate credit to the original author(s) and the source, provide a link to the Creative Commons licence, and indicate if changes were made. The images or other third party material in this article are included in the article's Creative Commons licence, unless indicated otherwise in a credit line to the material. If material is not included in the article's Creative Commons licence and your intended use is not permitted by statutory regulation or exceeds the permitted use, you will need to obtain permission directly from the copyright holder. To view a copy of this licence, visit http://creativecommons.org/licenses/by/4.0/. The Creative Commons Public Domain Dedication waiver (http://creativecommons.org/publicdomain/zero/1.0/) applies to the data made available in this article, unless otherwise stated in a credit line to the data. 
Workforce health can be measured in two ways. The first is the self-assessment of health status, which can more intuitively reflect the health status of individuals, show a closer relationship with studies on individual choices such as labor force participation and retirement, and acquire data more easily [1-3]. The second is the construction of comprehensive indicators. Regarding activities of daily living (ADLs), little variation in young populations is shown [4]. The Short Form 36 (SF-36) health survey questionnaire [5], Euroqol-5D [6], Health Utilities Index (HUI) [7], and Quality of Well-Being Scale (QWB) [8] which includes objective indicators based on individual health status, are also limited. Reflecting an individual's subjective assessment of his or her health status, quality of life indicators are very rigorous in their data requirements. Subjective measures, such as self-assessed health (SAH) or satisfaction with one's own health, provide valuable insights because they might respond more quickly to changes in working time than objective indicators, such as the frequency of doctor visits or absences from work due to sickness.

Since the 1980s, working hours have been a matter of debate and have become a focal issue in Canada, France, Germany, the United States, the United Kingdom, and other Western countries $[9,10]$. As a universal phenomenon among most organizations and companies, longer working hours are motivated by the possibility of job advancement or better employment opportunities and higher wages. According to efficiency wage theory, the cost of unemployment is positively correlated with the number of working hours, whose increase is an important indication of work effort but can be harmful to the health of the population above a certain level, with some degree of overtime being associated with high levels of stress and health effects accumulating over time [11-15].

In general, related studies emphasize that health suffers from underemployment and, in particular, unemployment [16-20]. In addition, an extensive literature documents that long working hours are closely related to chronic diseases, poor mental health and unhealthy behaviors such as smoking and alcohol consumption [21-25]. Epidemiological research has shown that long working hours affect the risk of cardiovascular diseases [26-29], stress, chronic fatigue [30], the probability of stroke [31], anxiety, sleep quality, all-cause mortality, smoking, hypertension, self-perceived health, health behaviors and mental health status [32, 33]. Regarding long working hours, similar results have been obtained by other studies, including myocardial infarction [34], injuries, poor physical health, alcohol consumption [35], physical inactivity [36], and depression [37]. In general, it has been found that long working hours are detrimental to health [38]. While studies conclude that additional working hours have adverse consequences for health, they predominantly focus on specific symptoms.

Mild differences between occupations in labor and heterogeneity in time commitment can have different effects on health, with more resources and energy invested in career development leading to more distinct occupational identities and highly complex jobs producing more significant effects on health [39]. Gender differences also exist in the effects of long working hours on health. Mainly due to the differences in the social roles and socioeconomic status of different gender groups, involuntary overwork is positively associated with the poor mental health of males but can lead to the poor physical health of females [40]. Long working hours can be detrimental to both individual and spousal health.

Despite the significance of long working hours, a meta-analysis conducted by Sparks and Cooper [25] discovered that a variety of health syndromes are slightly positively correlated with long working hours based on a relevant literature review. The research perspectives were mostly analyzed based on one aspect, such as the relationship between long working hours and the health status of a certain group of migrant workers, while heterogeneity analysis focused on special groups and occupational types. No subsequent research on the association between long working hours and health or combined medical insurance has been conducted. The issue of long working hours is quite important in every society, which thus highlights the need to investigate the connection between long working hours and the health of workers. Moreover, the link between long working hours and health is rarely studied from the perspective of different genders or educational levels.

Given the insufficient understanding of some details of this issue, this study investigated the association between long working hours and self-rated health (SRH) using data from the China Family Panel Studies (CFPS). This study aimed to examine (1) the definition of long working hours and (2) whether long working hours are associated with $\mathrm{SRH}$, with particular attention to differences in gender and education.

\section{Data and methods}

\section{Data}

Involving 25 provinces, municipalities, and autonomous regions, the data adopted in this paper were sourced from the CFPS and four main questionnaires, namely, community, family, adult, and child questionnaires, which can be used for research on individual microbehaviors. In this paper, the 2016 and 2018 data were combined for a panel data analysis based on the nonfarm labor force aged 18-65 as subjects. A total of 6972 valid samples were obtained after the deletion of missing, extreme, and unreasonable values. 


\section{Measurement of the variables}

\section{Measurement of the health level of the labor force}

In this study, the outcome variable was the SRH level. The question "What do you consider your health to be?" was chosen to measure the health level of the labor force based on the design of the CFPS questionnaire. The response options were "unhealthy", "fair", "relatively healthy", "healthy" and "very healthy", which were assigned a value of $1,2,3,4$ and 5, respectively. As shown in Table 1, the average SRH level of the respondents was fair.

\section{Measurement of long working hours}

In this paper, the core explanatory variable was long working hours. Based on the design of the CFPS questionnaire, the question "How many hours a week does this job typically involve?" was chosen to measure working hours. Referring to the related Chinese and international research and according to the working time restrictions in the Labor Law of China, this paper used a working time of more than 50 working hours a week as the standard for identifying long working hours. Articles 36,38 , and 41 of the Labor Code stipulate that a worker should not work more than $8 \mathrm{~h}$ a day and $44 \mathrm{~h}$ a week on average. Employers should ensure at least 1 day of rest per week for workers. Employers may extend working hours, which should generally not exceed 1 hur per day for production and business purposes, as suggested by the worker and trade union; additionally, if there is a need to extend work hours for special reasons, employers should not extend working hours more than $3 \mathrm{~h}$ per day and more than $36 \mathrm{~h}$ per month to guarantee the physical health of workers. As a result, the reference standard working time is $44 \mathrm{~h}$, and the maximum weekly working time can be $44+1 * 6=50 \mathrm{~h}$ in view of production and operational needs. Therefore, in this paper, a working time of more than $50 \mathrm{~h}$ a week for workers was regarded as overwork, which is consistent with the standard of measuring overwork in China and internationally. As illustrated in Table 1, the labor force works $52 \mathrm{~h}$ a week, exceeding the working hours standard.

\section{Measurements of the covariates}

To reduce the underlying bias in the statistical model caused by omitted variables, the empirical analysis controlled for variables including gender, age, educational level, personal income, marital status, smoking, drinking, exercise frequency, and medical insurance participation, which are specifically defined in Table 1.

\section{Ordered Probit model}

This paper focused on the relationship between long working hours and the physical health of the labor force, and the explanatory variable, SRH, as multi-ordered data, was unsuitable for ordinary least squares (OLS) estimation. As an extension of the probit model dealing specifically with cases in which the interpreted variable is sorted data, the following model was set:

$$
\text { health }_{i, t}=F\left(\text { Blongworkinghours }_{i, t}+\gamma X_{i, t}+\varepsilon_{i, t}\right)
$$

where health ${ }_{i, t}$ represents the dependent variable; $\beta$ refers to the intercept term; $X_{i, t}$ means a series of control

Table 1 Definition of variables and descriptive statistics

\begin{tabular}{|c|c|c|c|c|c|c|c|}
\hline \multirow[t]{2}{*}{ Variables } & \multirow[t]{2}{*}{ Definition } & \multicolumn{2}{|c|}{$\begin{array}{l}\text { Full sample } \\
(N=6972)\end{array}$} & \multicolumn{2}{|c|}{$\begin{array}{l}\text { Working hours } \\
\text { are less than } 50 \mathrm{~h} \\
(\mathrm{~N}=3419)\end{array}$} & \multicolumn{2}{|c|}{$\begin{array}{l}\text { Working hours } \\
\text { not less than } 50 \\
\mathrm{~h}(\mathrm{~N}=3553)\end{array}$} \\
\hline & & Mean & $\begin{array}{l}\text { Standard } \\
\text { Error }\end{array}$ & Mean & $\begin{array}{l}\text { Standard } \\
\text { Error }\end{array}$ & Mean & $\begin{array}{l}\text { Standard } \\
\text { Error }\end{array}$ \\
\hline Self-rated health & $\begin{array}{l}\text { Unhealthy }=1 \text {, fair }=2 \text {, relatively healthy }=3 \text {, } \\
\text { healthy }=4 \text {, very healthy }=5\end{array}$ & 3.21 & 1.05 & 3.23 & 1.01 & 3.19 & 1.10 \\
\hline Long work hours & Whether working time is less than $50 \mathrm{~h}$ & 0.51 & 0.5 & - & - & - & - \\
\hline Gender & Male $=1$, female $=0$ & 0.29 & 0.46 & 0.26 & 0.44 & 0.33 & 0.47 \\
\hline Age & age & 36.74 & 11.06 & 36.38 & 11.03 & 37.08 & 11.09 \\
\hline Income & Annual personal income & 8.42 & 4.03 & 9.06 & 3.55 & 7.80 & 4.36 \\
\hline Level of education & $\begin{array}{l}\text { Junior secondary and below }=1 \text {, senior } \\
\text { secondary/technical school/vocational } \\
\text { high school }=2 \text {, junior college and above }=3\end{array}$ & 1.84 & 0.88 & 2.15 & 0.89 & 1.54 & 0.77 \\
\hline Marital status & At the wedding $=1$,otherwise $=0$ & 0.80 & 0.40 & 0.77 & 0.42 & 0.82 & 0.39 \\
\hline Whether to smoke or not & Smoking $=1$, otherwise $=0$ & 0.05 & 0.22 & 0.04 & 0.19 & 0.06 & 0.24 \\
\hline Whether to drink or not & Three times a week in the past month $=1$ & 0.07 & 0.25 & 0.06 & 0.24 & 0.08 & 0.27 \\
\hline Exercise Frequency & How many times a week do you do exercise & 2.16 & 2.92 & 2.40 & 2.93 & 1.93 & 2.89 \\
\hline Whether you have health insurance or not & Health Insurance $=1, \mathrm{No}=0$ & 0.90 & 0.30 & 0.91 & 0.29 & 0.89 & 0.31 \\
\hline
\end{tabular}


variables; $\gamma$ represents for the coefficient of the influence of these control variables on the health level of the respondents; $\varepsilon_{i, t}$ is a random error term; and $\mathrm{F}($.$) denotes$ a nonlinear function that takes the following form:

$$
\mathrm{F}\left(y_{i, t}^{*}\right)=\left\{\begin{array}{cc}
1 & y_{i, t}^{*} \leq C_{1} \\
2 & C_{1}<y_{i, t}^{*} \leq C_{2} \\
\mathrm{M} & \mathrm{M} \\
J & y_{i, t}^{*}>C_{j-1}
\end{array}\right.
$$

where $y_{i, t}^{*}$ represents the latent variable, satisfying

$$
y_{i, t}^{*}=\beta \text { workhour }_{i, t}+\gamma X_{i, t}+\varepsilon_{i, t}
$$

$\mathrm{C}_{1}<\mathrm{C}_{2}<\ldots<\mathrm{C}_{\mathrm{J}-1}$ are tangent points and parameters to be estimated.

$$
\begin{aligned}
& \mathrm{P}\left(\mathrm{y}_{i, t}=1 \mid X_{i, t}\right)=P\left(y_{i, t}^{*}<C_{1}\right) \\
& \mathrm{P}\left(\mathrm{y}_{i, t}=2 \mid X_{i, t}\right)=P\left(C_{1} \leq y_{i, t}^{*}<C_{2}\right) \\
& \mathrm{P}\left(\mathrm{y}_{i, t}=3 \mid X_{i, t}\right)=P\left(C_{2} \leq y_{i, t}^{*}<C_{3}\right) \\
& \mathrm{P}\left(\mathrm{y}_{i, t}=J \mid X_{i, t}\right)=1-P\left(C_{n-2} \leq y_{i, t}^{*}<C_{n-1}\right)
\end{aligned}
$$

If the random error term is in the normal distribution, the probability of a higher health level of the labor force will increase.

A causal relationship may exist between long working hours and other variables such as health. For example, a person will find it difficult to work if he or she is not in a healthy state. To solve the endogeneity of long working hours and to identify the econometric model, whether the average working time of industry is less than $50 \mathrm{~h}$ was used as the instrumental variable of working time. Whether the working time in the same trade is too long will affect the working time of individuals but have no impact on the health of individuals. However, in this paper, health is a discrete variable, and two-stage least squares based on a continuous variable may fail [41]. Therefore, conditional mixed process (CMP) regression analyses and extended regression models (ERMs) that can handle endogeneity were used to re-estimate the baseline regression model.

\section{Results}

The regression results of the relationship between long working hours and the health level of individuals are reported in Table 2. Columns (1)-(3) are the ordered probit (oprobit), ERM, and CMP regressions results, which suggest that, all other things being equal, long working

\begin{tabular}{|c|c|c|c|}
\hline & OPROBIT & ERM & CMP \\
\hline \multirow[t]{2}{*}{ Long working hours } & $-0.0519^{*}$ & $-0.0729^{*}$ & $-0.0681^{* *}$ \\
\hline & $(0.090)$ & $(0.050)$ & $(0.047)$ \\
\hline \multirow[t]{2}{*}{ Gender } & $0.150^{* * *}$ & $0.151^{* * *}$ & $0.139^{* * *}$ \\
\hline & $(0.000)$ & $(0.000)$ & $(0.000)$ \\
\hline \multirow[t]{2}{*}{ Age } & $-0.0275^{* * *}$ & $-0.0274^{* * *}$ & $-0.0254^{* * *}$ \\
\hline & $(0.000)$ & $(0.000)$ & $(0.000)$ \\
\hline \multirow[t]{2}{*}{ Income } & $0.00772^{* *}$ & $0.00764^{* *}$ & $0.00718^{* *}$ \\
\hline & $(0.035)$ & $(0.045)$ & $(0.039)$ \\
\hline \multirow[t]{2}{*}{ Level of education } & -0.0182 & -0.0180 & -0.0163 \\
\hline & $(0.334)$ & $(0.324)$ & $(0.334)$ \\
\hline \multirow[t]{2}{*}{ Marital status } & 0.0519 & 0.0516 & 0.0481 \\
\hline & $(0.182)$ & $(0.176)$ & $(0.169)$ \\
\hline \multirow[t]{2}{*}{ Smoking } & $-0.138^{* *}$ & $-0.138^{* *}$ & $-0.129^{* *}$ \\
\hline & $(0.043)$ & $(0.039)$ & $(0.035)$ \\
\hline \multirow[t]{2}{*}{ Drinking } & $0.133^{* *}$ & $0.132^{* *}$ & $0.123^{* *}$ \\
\hline & $(0.022)$ & $(0.026)$ & $(0.024)$ \\
\hline \multirow[t]{2}{*}{ Exercise } & $0.0264^{* * *}$ & $0.0263^{* * *}$ & $0.0246^{* * *}$ \\
\hline & $(0.000)$ & $(0.000)$ & $(0.000)$ \\
\hline \multirow[t]{2}{*}{ Medical insurance } & -0.0662 & -0.0297 & -0.0276 \\
\hline & $(0.168)$ & $(0.607)$ & $(0.606)$ \\
\hline Year & YES & YES & YES \\
\hline Province & YES & YES & YES \\
\hline sigma2_u & 0.168 & & \\
\hline _cons & $(0.310)$ & & \\
\hline \multirow[t]{2}{*}{$\mathrm{n}$} & & $0.834^{* * *}$ & $0.834^{* * *}$ \\
\hline & & $(0.000)$ & $(0.000)$ \\
\hline \multirow[t]{2}{*}{ _cons } & & $0.106^{* * *}$ & \\
\hline & & $(0.000)$ & \\
\hline Log likelihood & & & $-10,170.721$ \\
\hline Wald & & $135.97^{* * *}$ & \\
\hline Observations & 6972 & 6972 & 6972 \\
\hline
\end{tabular}
hours were negatively correlated with health across the entire sample; these results were significant at the 5$10 \%$ levels. An increase in working hours will diminish
Table 2 Relationship between long working hours and individual health level

Notes: $p$ value in parentheses; ${ }^{*} p<0.1,{ }^{* *} p<0.05$ and ${ }^{* * *} p<0.01$.

returns and lead to a decline in the SRH of the workforce.

The OLS and endogeneity processing model results show that long working hours are harmful to health.

The analysis above shows that the health level of the labor force is constrained by long working hours, but individuals' behavior is generally dominated by their beliefs, value orientation and attitudes towards realistic interests. Different cultures form different ideas and lifestyles, which ultimately exerts a direct or indirect impact on people's health. Thus, the impact of long working hours on the health level of the labor force varies by gender and education. 
Table 3 divides the sample by educational level and gender and further reports the relationship between long working hours and the health level of the labor force among different samples grouped by gender and educational level. From the perspective of differences in educational level, long working hours have a more significant impact on the SRH of workers with a college degree or above and a limited impact on the SRH of workers with other levels of educational attainment. From the perspective of gender differences, long working hours have a more significant influence on the SRH of male workers, with this result being significant at the $1 \%$ level.

\section{Discussion}

This paper focused on investigating the impact of long working hours on the health of the workforce using the CMP regression analyses. Based on the literature on the effects of workforce health levels, the variables were strictly controlled to address the estimation bias resulting from omitted variables and to ensure that the results were credible.
The health of the workforce depends on the combination of long working hours, education, income levels and other individual characteristics

Across the entire sample, long working hours were negatively correlated with health, that finding is consistent with previous reports $[3,36]$. An increase in working hours will diminish returns and lead to a decline in the $\mathrm{SRH}$ of the workforce. By participating in work activities, workers can give full play to their physical and social functions, but they can no longer obtain a sense of pleasure and belonging. Even if wage returns increase, the mental and physical strength of the workforce will be impaired. A gradual decline in the SRH level of the labor force will occur, increasing the risk factors for depression, hypertension, and other diseases [26, 42, 43].

\section{Participation in medical insurance has no significant effect on self-rated health}

Across the entire sample, long working hours were negatively correlated with health, and participation in medical insurance failed to significantly improve the SRH

Table 3 Relationship between long working hours and the self-rated health of workforce among different age stages and education levels

\begin{tabular}{|c|c|c|c|c|}
\hline & Below junior college & Tertiary and above & Male & Female \\
\hline \multirow[t]{2}{*}{ Long working hours } & 0.0167 & $-0.294^{* * *}$ & $-0.156^{* *}$ & -0.0394 \\
\hline & (0.709) & $(0.000)$ & $(0.022)$ & $(0.325)$ \\
\hline \multirow[t]{2}{*}{ Gender } & $0.158^{* * *}$ & $0.132^{* *}$ & - & - \\
\hline & $(0.000)$ & $(0.013)$ & - & - \\
\hline \multirow[t]{2}{*}{ Age } & $-0.0236^{* * *}$ & $-0.0329^{* * *}$ & $-0.0223^{* * *}$ & $-0.0273^{* * *}$ \\
\hline & $(0.000)$ & $(0.000)$ & $(0.000)$ & $(0.000)$ \\
\hline \multirow[t]{2}{*}{ Income } & $0.00865^{* *}$ & -0.00458 & $0.0126^{* *}$ & 0.00459 \\
\hline & $(0.019)$ & $(0.578)$ & $(0.047)$ & $(0.272)$ \\
\hline \multirow[t]{2}{*}{ Level of education } & & & -0.0347 & -0.00783 \\
\hline & & & $(0.265)$ & (0.698) \\
\hline \multirow[t]{2}{*}{ Marital status } & 0.0544 & 0.0789 & 0.0108 & 0.0522 \\
\hline & $(0.252)$ & $(0.175)$ & $(0.864)$ & $(0.221)$ \\
\hline \multirow[t]{2}{*}{ Smoking } & -0.107 & $-0.245^{*}$ & -0.0980 & $-0.361^{* *}$ \\
\hline & $(0.140)$ & $(0.054)$ & $(0.133)$ & $(0.041)$ \\
\hline \multirow[t]{2}{*}{ Drinking } & 0.0893 & $0.235^{* *}$ & $0.167^{* *}$ & 0.0202 \\
\hline & $(0.136)$ & $(0.047)$ & $(0.011)$ & $(0.841)$ \\
\hline \multirow[t]{2}{*}{ Exercise Frequency } & $0.0164^{* * *}$ & $0.0564^{* * *}$ & $0.0312^{* * *}$ & $0.0222^{* * *}$ \\
\hline & $(0.002)$ & $(0.000)$ & $(0.001)$ & $(0.000)$ \\
\hline \multirow[t]{2}{*}{ Medical Insurance } & -0.0925 & 0.0942 & 0.101 & -0.0705 \\
\hline & $(0.228)$ & $(0.306)$ & $(0.316)$ & $(0.265)$ \\
\hline Year & YES & YES & YES & YES \\
\hline Province & YES & YES & YES & YES \\
\hline Observations Observations & 4722 & 2250 & 2053 & 4919 \\
\hline Log likelihood & -6889.171 & -2976.8187 & -3117.2115 & -6990.6308 \\
\hline
\end{tabular}

Notes: $p$ value in parentheses; ${ }^{*} p<0.1,{ }^{* *} p<0.05$ and ${ }^{* * *} p<0.01$. 
level of the labor force In fact, it showed a downward trend. With a security model oriented towards "treatment, prevention, hospitalization and outpatient care", China's medical insurance system ignores disease prevention and outpatient treatment, and it fails to intervene in the workforce in a timely manner to eliminate the causes of workers' physical discomfort. In China, the basic medical insurance for urban workers mainly covers inpatient medical expenses beyond the minimum payment line, and medical expenses exceeding the maximum payment line need to be paid by individuals. In some regions, medical expenses for general outpatient care are paid by individual or individual account of medical insurance. In order not to delay working hours or save expenses, the workforce physical appear "Minor illness pain" more choice to wait for disease self-cure or buy medicine self-treatment, coupled with the labor force to disease prevention awareness is not strong, health level can not be improved. The medical insurance system "focus on treatment, neglect prevention "of the security model ignored in the physical examination, maintenance and promotion of health protection.

\section{The relationship between long working hours and self- rated health varies by education and gender}

The study also demonstrates that long working hours have a more significant impact on the SRH of workers with higher levels of educational attainment. To some extent, the increase in the working hours of workers with higher educational levels is detrimental to their level of health, this is also supported by many other studies conducted in Korea [44], possibly because of the psychological pressure exerted by the self-expectations that they hold with regard to their occupations as well as the difference between giving and receiving. A difference can be found in the time allocation between rest and workdays. The key to the decline in SRH lies in the factors that influence the physical and psychological aspects of an individual, such as a lack of exercise, an unreasonable diet, and working conditions that involve chronic exposure to computer radiation. Workers with lower educational levels are mostly engaged in alternative work or repetitive manual labor, while those with lower skill levels are concentrated in low-end laborintensive industries and services. Increased working hours have a limited impact on the health of these workers.

Long working hours had a significant impact on the health of the male labor force. In the distribution of family roles, males have traditionally been breadwinners, focusing more on their careers and being more susceptible to workplace stressors $[45,46]$. Men have to endure more stress and work longer hours than women, while women are more likely to play multiple roles at work and at home. Longer working hours have a limited impact on the health of women.

\section{Conclusions}

Using the nonfarm employed workforce and the 2016 and 2018 waves of the CFPS, this paper examined the relationship between long working hours and workforce health through the lens of working hours. It found that long working hours were negatively correlated with health and had a more significant impact on the SRH of workers with higher levels of educational attainment. The effects of long working hours on the SRH of the workforce vary by education and gender. This finding has great implications for future research, which should pay attention to regulating working time, carrying out a comprehensive health and hygiene education.

This study offers several implications for working time regulations and overtime rules to protect workers' health. In the short term, it may seem that long working hours for employees may be beneficial for maximizing the profits of companies, and increased working hours may result in higher performance. However, health is an important human capital factor for workers, and long working hours cannot contribute to sustained productivity gains over a longer period. They lead to an excessive drain on the personal energy of workers, crowding out time that could be spent to invest in health and resulting in more work stress. This phenomenon can cause more work and mental stress and physical health problems, and it can even lead to the forced cessation of work. The analysis in this paper shows that the average working hours of the workforce exceed the requirements of the Labor Law of China, which thus makes it necessary to limit the excessive working hours of the workforce and promote the regularization of working hours in the labor market. Moreover, the regulations related to overtime hours should be further standardized, and employers should pay wages for the overtime hours of the workforce based on relevant legal standards to reduce the damage of excessive working hours to the health level of the workforce and to facilitate the balance between workers' work and nonwork days.

Although it is consistent with the characteristics of most Western countries in the period of rapid economic development, excessive labor harms the interests of workers and sustainable economic development. While maintaining sustained and healthy economic development, on the one hand, the government should raise the knowledge levels and skills of workers through formal education and vocational training, targeting workers with lower skill levels to increase their productivity. On the other hand, higher education should be the key to solving the health problems associated with education. Carrying out health education in universities and 
changing life habits that are harmful to health provide directions for deepening the comprehensive hygiene education in China.

The empirical analysis shows that whether the labor force participates in health insurance has no significant impact on workers' SRH. From the promulgation of the Opinions on the Overall Planning of the Basic Medical Insurance System for Urban and Rural Residents to the completion of the integration of the system in the vast majority of regions in China, medical insurance has been able to meet more medical needs and has expanded its coverage, basically achieving the goal of universal health insurance. However, some problems remain to be solved in the implementation of China's basic medical insurance system, which was originally established with the intention that all individuals facing the risk of diseases should share the risk to resist the financial and health impacts brought by diseases. Compared with commercial medical insurance, basic medical insurance can solve the problem of adverse selection. However, China has set up a basic medical insurance system for different groups of people instead of implementing a single basic medical insurance system. In terms of the payment for and treatment provided by basic medical insurance, there exists a large gap between urban workers and urban and rural residents. If they are able to make a choice, some healthy young people will choose to participate in the basic medical insurance of urban and rural residents, which involves low payment levels. To reduce the resistance of system integration, many regions have adopted the policy of "Single System, Multi-Standard". Based on the premium level chosen, insured individuals can enjoy the corresponding treatment provided by medical insurance $[47,48]$. In practice, the "Single System, Multi-Standard" can easily cause an adverse selection of insured individuals, who will choose a high premium level if in poor health, which is not conducive to the long-term stable operation of health insurance funds. As a measure for promoting the integration of the basic medical insurance system, it is important to abolish the practice of "Single System, Multi-Standard", increase the financial subsidies of low-income groups, ensure the full coverage of basic medical insurance, and truly unify the reimbursement provided by medical insurance.

\footnotetext{
Acknowledgments

The authors would like to thank the China Family Panel Studies (CFPS) for providing excellent research data. All remaining errors are those of the authors. In a special way also thank Prof. Zhang Qi of the Capital University of Economics and Business for her advice during discussion and conclusion analysis in this study.
}

\section{Author's contributions}

The literature review, methods, and data collection and analysis sections were written by L.C., and L.C. commented on previous versions of the manuscript. L.C. has read and agreed to the published version of the manuscript. The author(s) read and approved the final manuscript.

\section{Funding}

This research received no external funding.

\section{Availability of data and materials}

The datasets used during the current study are available from the website of the Institute of Social Science Survey (http://isss.pku.edu.cn/cfps/download/ login) and can be accessed by registering to access the study data. The datasets analyzed during the current study are available from the corresponding author upon reasonable request.

\section{Declarations}

Ethics approval and consent to participate

Not applicable.

Consent for publication

Not applicable.

\section{Competing interests}

The author declares no conflict of interest.

Received: 29 December 2020 Accepted: 27 May 2021

Published online: 07 July 2021

\section{References}

1. Berniella I, Bietenbeck J. The effect of working hours on health. Econ Hum Biol. 2020;39:1-39.

2. Cygan-Rehm K, Wunder C. Do working hours affect health? Evidence from statutory workweek regulations in Germany. 2018;53:162-71.

3. Song J-T, Lee G, Kwon J, Park J-W, Choi H, Lim S. The association between long working hours and self-rated health. Ann Occup Environ Med. 2014; 26(2):1-12.

4. Collin C, Wade DT, Daves $\mathrm{S}$, et al. The barthel ADL index;A reliability study. Int Disabil Stud. 1988;10(2):61-3.

5. Brazer J, Usherwood T, Harper R. Deriving A preference based single index from the UK SF-36 health survey. Clin Epidemiol. 1998;11:1115-28. https:// doi.org/10.1016/s0895-4356(98)00103-6.

6. JV BJ, Mcdonnell J, Essink-Bot ML. Estimating parametric relationships between health description and health valuation with an application to the EuroQol EQ-5D. J Health Econ. 1999;5:551-71. https://doi.org/10.1016/s01676296(99)00008-9.

7. Feeny D, Furlong W, Torrance G, Goldsmith CH, Zhu ZL, DePauw S, et al. Multiattribute and single attribute utility functions for the health utilities index mark 3 system. Med Care. 2002;2:113-28. https://doi.org/10.1097/ 00005650-200,202,000-00006

8. Rm K, Sieber WJ, Ganiates TG. The quality of wellbeing scale:comparison of the interview administers questionnaire. Psychol Health. 1997;2:783-91. https://doi.org/10.1093/intahc/10.6.509.

9. Lee S, McCann D, Messenger JC. Working Time Around the World. Trend in Working Hours, Laws and Policies in a Global Comparative Perspective. Geneva, Switzerland: International Labour Office; 2007.

10. Burger, A.S. Extreme Working Hours in Western Europe and North America: A New Aspect of Polarization.The London School of Economics and Political Science No. 92, 52. 2015. Available online:http://www.Ise.ac.uk/europea nInstitute/LEQS\%20Discussion\%20Paper\%20Series/LEQSPaper92.pdf.

11. Warr P. Work, Happiness,and Unhappiness. London: PsychologyPress; 2007.

12. Artazcoz L, Cortès I, Escribà-Agüir V, Cascant L, Villegas R. Understanding the relationship of long working hours with health status and health-related behaviours. J Epidemiol Community Health. 2009;63(7):521-7. https://doi. org/10.1136/jech.2008.082123.

13. Toon W, Taris Michiel A J,Kompier Sabine AE, Geurts Irene L. D Houtman Floor F M, Van Den Heuvel. Professional efficacy,exhaustion, and work characteristics among police officers: a longitudinal test of the learningrelated predictions of the demand-control model. J Occup Organ Psychol, 2010, 83(2):455-474.doi: https://doi.org/https://doi.org/10.1348/09631 $7909 \times 424583$.

14. Nixon AE, Mazzola JJ, Bauer J, Krueger JR, Spector PE. Can work make you sick? A metaanalysis of the relationships between job stressors and physical symptoms. Work Stress. 2011;25(1):1-22.

15. Qingbo $H$, Zhihong S. Migrant workers working hours and their physical and mental health. Chin J Health Psychol J. 2015;3:358-62. 
16. Winkelmann L. and R. Winkelmann.Why are the unemployed so unhappy? Evidence from panel data. Economica. 1998;65(257):1-15.

17. Petri P. Unemployment and self-assessed health:evidence from penel data. Health Econ. 2009;18:161-79.

18. Wunder C, Heineck G. Working time preferences, hours mismatch and wellbeing of couples: Are there spillovers? Labour Econ. 2013:24:244-52.

19. Aghion P, Akcigit U, Deaton A, Roulet A. Creative destruction and subjective well-being. Am Econ Rev. 2016;106(12):3869-97.

20. Cygan-Rehm K, Kuehnle D, Oberfichtner M. Bounding the causal effect of unemployment on mental health: Nonparametric evidence from four countries. Health Econ. 2017;26(12):1844-61.

21. Ahn T. Reduction of working time: Does it lead to a healthy lifestyle? Health Econ. 2015;29:969-83.

22. Llena-Nozal A. The effect of work status and working conditions on mental health in four OECD countries. Natl Inst Econ Rev. 2009:209(1):72-87. https://doi.org/10.1177/0027950109345234.

23. Virtanen M, Heikkilä K, Jokela M, Ferrie JE, Batty GD, Vahtera J, et al. Long working hours and coronary heart disease: a systematic review and metaanalysis. Am J Epidemiol. 2012;176(7):586-96.

24. Magee CA, Caputi P, Iverson DC. Short sleep mediates the association between long work hours and increased body mass index. J Behav Med. 2011;34(2):83-91. https://doi.org/10.1007/s10865-010-9287-3.

25. Xiaowei $Y$, Hongwei $H$, Zhenhua W, Jing S. Study on health status and influencing factors of urban residents in China.China's population, resources and environment. 2010;2:151-6.

26. Tamakoshi BA, A. The association between long working hours and health: A systematic review of epidemiological evidence. Scand. J. Work Environ. Health. 2014:40:5-18.

27. Liu Y, Tanaka H. Overtime work, insufficient sleep, and risk of non-fatal acute myocardial infarction in Japanese men. Occup. Environ. Med. 2002;59:44751.

28. Sparks K, Cooper C, Fried Y, Shirom A. The effects of hours of work on health: A meta-analytic review.J. Occup. Organ. Psychol. 1997;70:391-408.

29. Uehata T. Long working hours and occupational stress-related cardiovascular attacks among middle-aged workers in Japan. J. Hum. Ergol. 1991:20:147-53.

30. White J, Beswick J. Working Long Hours. Sheffield, UK: Health and Safety Laboratory; 2003.

31. Kivimäki M, Jokela M, Nyberg ST, Singh-Manoux A, Fransson El, Alfredsson L, et al. Long working hours and risk of coronary heart disease and stroke: A systematic review and meta-analysis of published and unpublished data for 603,838 individuals. The Lancet. 2015;386:1739-46.

32. Siegrist J, Rödel A. Work stress and health risk behavior. Scand J Work Environ Health. 2006:32(6):473-81.

33. Taris TW, Ybema JF, Beckers DG, Verheijden MW, Geurts SA, Kompier MA. Investigating the associations among overtime work, health behaviors, and health: a longitudinal study among full-time employees. Int J Behav Med. 2011;18:352-60.

34. Fukuoka Y, Dracup K,Froelicher E.S,Ohno M.,Hirayama H.,Shiina H, Kobayashi F. Do Japanese workers who experience an acute myocardial infarction believe their prolonged working hours are a cause? Int. J. Cardiol.2005;100: 29-35.

35. Grosch JW, Caruso CC, Rosa RR, Sauter SLW. Long hours of work in the US: Associations with demographic and organizational characteristics, psychosocial working conditions, and health. Am. J.Ind. Med. 2006:49:943-952.

36. Lallukka T, Lahelma E, Rahkonen O, Roos E, Laaksonen E, Martikainen P, et al. Associations of job strain and working overtime with adverse health behaviors and obesity: Evidence from the Whitehall II Study, Helsinki Health Study, and the Japanese Civil Servants Study. Soc. Sci. Med. 2008;66:1681-98.

37. Kim, W; Park, E.C.; Lee, T.H.; Kim, T.H. Effect of working hours and precarious employment on depressive symptoms in South Korean employees: A longitudinal study. Occup Environ Med. 2016;73:816-822.

38. Van der Hulst M. Long workhours and health. Scand J Work, Environment and Health. 2003:29:171-88.

39. Fein $\mathrm{E}$, Skinner N. Clarifying the effect of work hours on health through work-life conflict. Asia Pac J Hum Resour. 2015:53(4):448-70.

40. Stolzenberg RM. It's about time and gender:spousal employment and health. Am J Sociol. 2001;107:61-100. https://doi.org/10.1086/323151.

41. Sajaia Z. Maximum Likelihood Estimation of a Bivariate Ordered Probit Model: Implementation and Monte Carlo Simulations. Stata J. 2008; $4(2): 1-18$.
42. Virtanen M, Ferrie JE, Singh-Manoux A, Shipley MJ, Stansfeld SA, Marmot $M G$, et al. Long working hours and symptoms of anxiety and depression: A 5-year follow-up of the Whitehall II study. Psychol Med. 2011;41:2485-94.

43. Park S, Lee J-H, Lee $\mathbf{W}$. The effects of workplace rest breaks on health problems related to long working hours and shift work among male apartment janitors in Korea. Saf Health Work. 2019;10:512-7.

44. Jongha J, Wanhyung L, Won-Jun C, Seunghon H, Seong-Kyu K. Association betweenWorking Hours and Self-Rated Health. Int J Environ Res Publc Health. 2020;17(8):2736-47.

45. Ransome P. Conceptualizing boundaries between 'life'and 'work'. Int J Hum Resour Manage. 2007;18(3):374-86

46. Artazcoz L, Borrell C, Cortès I, Escribà-Agüir V, Cascant L. Occupational epidemiology and work related inequalities in health: a gender perspective for two complementary approaches to work and health research. J Epidemiol Community Health. 2007;61(2):ii39-45.

47. Yi Pei, Zhang Wei. Integration of Social Health Insurance Program: "Single System, Multi-Standard" or "Single System, Single-Standard". J Pub Manage. 2018;4(15):80-91

48. Peng Haoran, Yue jinglun. Integration of China's Basic Medical Insurance System: Theoretical Debate, Practical Progress and Future Prospects. Academic Monthly. 2020;11(52):55-65.

\section{Publisher's Note}

Springer Nature remains neutral with regard to jurisdictional claims in published maps and institutional affiliations.
Ready to submit your research? Choose BMC and benefit from:

- fast, convenient online submission

- thorough peer review by experienced researchers in your field

- rapid publication on acceptance

- support for research data, including large and complex data types

- gold Open Access which fosters wider collaboration and increased citations

- maximum visibility for your research: over $100 \mathrm{M}$ website views per year

At BMC, research is always in progress.

Learn more biomedcentral.com/submissions 